Revista Eletrônica de Direito Processual - REDP.

Rio de Janeiro. Ano 10. Volume 17. Número 2. Julho a Dezembro de 2016

Periódico Semestral da Pós-Graduação Stricto Sensu em Direito Processual da UERJ

Patrono: José Carlos Barbosa Moreira. ISSN 1982-7636. pp. 406-419

www.redp.uerj.br

\title{
O NOVO CÓDIGO DE PROCESSO CIVIL BRASILEIRO: UM CÓDIGO DE PRINCÍPIOS ${ }^{1}$
}

\section{THE NEW BRAZILIAN CIVIL PROCEDURE CODE: A CODE OF PRINCIPLES}

\section{Leonardo Oliveira Soares}

Procurador do Estado de Minas Gerais, atualmente na condição de Advogado Regional em Ipatinga. Mestre em Direito Processual pela PUC-MG. Membro da Academia Brasileira de Direito Processual e do Instituto dos Advogados de Minas Gerais. Professor de Teoria Geral do Processo e Processo Civil na Faculdade de Direito de Ipatinga (MG).

soares.leonardooliveirasoares@gmail.com

RESUMO: No artigo, após breve contextualização histórica, foram examinados os princípios fundamentais do CPC/2015.

PALAVRAS-CHAVE: Novo Código de Processo Civil brasileiro, princípios fundamentais, celeridade processual, Estado Democrático de Direito.

ABSTRACT: The fundamental principles of the new Brazilian Civil Procedure Code were examined in this article, after a brief historical context.

KEYWORDS: New Brazilian Civil Procedure Code, fundamental principles, celerity of the proceedings, Democratic State of Law.

SUMÁRIO: 1. Introdução. 2. Breve Contextualização. 3. Visão sistêmica do CPC/2015, a partir de suas normas fundamentais. 3.1 Princípio da inafastabilidade.3.2. Princípio da primazia do julgamento de mérito e da duração razoável do processo. 3.3. Princípios da boa fé e da cooperação. 3.4. Princípio do contraditório dinâmico. 3.5. Princípio da

\footnotetext{
${ }^{1}$ Artigo recebido em 29/08/2016 e aprovado em 27/09/2016.
} 
Revista Eletrônica de Direito Processual - REDP.

Rio de Janeiro. Ano 10. Volume 17. Número 2. Julho a Dezembro de 2016

Periódico Semestral da Pós-Graduação Stricto Sensu em Direito Processual da UERJ

Patrono: José Carlos Barbosa Moreira. ISSN 1982-7636. pp. 406-419

www.redp.uerj.br

transparência ou da impessoalidade processual. 3.6. Princípio da aplicação imediata. 3.7.

Princípio da subsidiariedade mitigada. 4. A título de conclusão.

A busca de delineamento de um sistema dogmático íntegro e adequado que leve a sério os princípios do modelo constitucional de processo e que aplique normas de tessitura aberta, torna imperiosa uma compreensão precisa da teoria dos princípios e da adequada leitura que o Novo CPC procura viabilizar para a melhoria do acesso à justiça democrático (Alexandre Franco Melo Bahia; Dierle Nunes; Flávio Quinaud Pedron e Humberto Theodoro Jr. NOVO CPC. Fundamentos e Sistematização. Lei 13.105, de 16.03.2015. 2. ed. rev., atual. e ampl. Rio de Janeiro: Forense. 2015).

\section{INTRODUÇÃO}

Após mais de cinco anos de tramitação no Congresso Nacional, foi sancionada e publicada no Diário Oficial da União de 17 de março de 2015, a Lei 13.105, por intermédio da qual foi criado o CPC/2015.

Em virtude do significativo alcance da mudança, previu o legislador, no art. 1.045, o prazo de um ano de vacatio legis.

Assim, em 18 de março de 2016, entrou em vigor cogitado diploma legal, ${ }^{2}$ que será, no texto, alvo de abordagem eminentemente jurídica.

Justifica-se a diretriz eleita para a exposição com uma razão muito simples, a saber: da mesma maneira que o ilegítimo funcionamento do Congresso Nacional pátrio não nos leva, necessariamente, à conclusão de que se deve fechar o Congresso e abandonar o sistema democrático representativo, crê-se que o insatisfatório funcionamento da justiça brasileira não seja motivo para considerar o instituto devido

\footnotetext{
${ }^{2}$ Considerado que a publicação da Lei 13.105 ocorreu em 17 de março de 2015 e o disposto no art. 8.,$\quad \S$ 1. ${ }^{\circ}$, da Lei complementar 95, de 26 de fevereiro de 1998, acrescentado pela Lei complementar 107, de 26 de abril de 2011, segundo o qual: "A contagem do prazo para entrada em vigor das leis que estabeleçam período de vacância far-se-á com a inclusão da data da publicação e do último dia do prazo, entrando em vigor no dia subsequente à sua consumação integral". Para chegar-se a essa conclusão, consideraram-se o prazo de 12 meses e a data de publicação da Lei 13.105, no caso, 17 de março de 2015. Vale frisar, o período de vacatio legis, demarcado em Lei, não foi computado em dias. Dessa maneira, a entrada em vigor ocorreu no primeiro dia útil subsequente: 18 de março de 2016.
} 
Revista Eletrônica de Direito Processual - REDP.

Rio de Janeiro. Ano 10. Volume 17. Número 2. Julho a Dezembro de 2016

Periódico Semestral da Pós-Graduação Stricto Sensu em Direito Processual da UERJ

Patrono: José Carlos Barbosa Moreira. ISSN 1982-7636. pp. 406-419

www.redp.uerj.br

processo legal como algo nocivo, prejudicial ao reconhecimento de direitos no Estado

Democrático de Direito brasileiro.

Dito isso, antes de tratar do tema de fundo do estudo, oportuno se afigura realizar ligeira contextualização histórica.

\section{BREVE CONTEXTUALIZAÇÃO}

Sabe-se que o CPC de 1973 foi elaborado para realidade institucional diversa, na qual a maior parte dos conflitos envolvia demandas individuais, de ordem patrimonial, a envolver, linhas gerais, as figuras de credor e devedor.

Além disso, o número de demandas àquela época sob apreciação do Poder Judiciário era infinitamente inferior ao quadro atual. ${ }^{3}$

Esse panorama, entretanto, foi sensivelmente modificado, notadamente com a promulgação da CF/1988.

De fato, pois a acertada constitucionalização de inúmeros novos direitos, aliada a inércia, a ineficácia mesma do Estado brasileiro em assegurar o cumprimento dos direitos fundamentais, originou explosão de demandas de toda sorte. Para ficar com um exemplo mais recente, basta pensar no fenômeno da chamada "judicialização da saúde".

Aliado a isso, e diante da complexidade das relações jurídicas oriundas de novos ramos do direito, por exemplo, o direito consumerista, surgiram e continuam a surgir demandas de massa ou, se preferir, repetitivas para as quais o Código de 1973 não oferecia soluções satisfatórias.

A rigor, nem mesmo faria sentido que o CPC então elaborado se ocupasse desses temas, já que, insista-se, regulava o funcionamento da justiça voltada para solucionar conflitos de natureza prioritariamente individual e de cunho patrimonialista.

Essa mudança de cenário, somada a deficiências de ordem de pessoal e de gerenciamento de demandas, levou o Poder Judiciário brasileiro, já na década de 90 do século passado, a experimentar série de dificuldades no desempenho de sua missão constitucional.

\footnotetext{
${ }^{3}$ De acordo com dados do Relatório Justiça em Números de 2015, aproximadamente 100 milhões de demandas, das quais $92 \%$ tramitam em primeiro grau de jurisdição. Disponível em: <http://www.cnj.jus.br/programas-e-acoes/politica-nacional-de-priorizacao-do-1-grau-dejurisdicao/dados-estatisticos-priorizacao>. Acesso em: 30.07.2016.
} 
Revista Eletrônica de Direito Processual - REDP.

Rio de Janeiro. Ano 10. Volume 17. Número 2. Julho a Dezembro de 2016

Periódico Semestral da Pós-Graduação Stricto Sensu em Direito Processual da UERJ

Patrono: José Carlos Barbosa Moreira. ISSN 1982-7636. pp. 406-419

www.redp.uerj.br

Para tentar debelar a crise, foram implementadas diversas reformas pontuais na legislação processual brasileira, v.g., as Leis 11.232/2005 e 11.238/2006.

Como não era difícil prever, tais reformas acabaram por desconfigurar a estrutura sistêmica primitiva do CPC, ora revogado.

Não bastassem esses argumentos, capazes (será?) por si só de justificar a elaboração de novo código, havia, também, a necessidade de redigir-se CPC que se apresentasse compatível com o modelo constitucional de processo previsto na Constituição brasileira de 1988.

Código, enfim, que estivesse de acordo com a denominada Carta Cidadã, apto, portanto, a oferecer tutela adequada às novas espécies de direitos fundamentais.

Independentemente das muitas críticas que o CPC/2015 comporta, como, de resto, toda e qualquer criação humana, é fato que nós, operadores do direito, a partir de 18 de março de 2016, estamos a vivenciar a experiência de atuar, pela primeira vez no Brasil, consoante regras do jogo democraticamente elaboradas.

Apresentada essa brevíssima visão panorâmica, já se pode lançar olhar sobre as diretrizes gerais do sistema criado.

Tal mirada leva em conta que uma das justificadas para a elaboração de novo CPC consistia precisamente em disponibilizar melhor organização do conjunto de regras disciplinadoras do exercício da jurisdição.

\section{VISÃO SISTÊMICA DO CPC/2015, A PARTIR DE SUAS NORMAS FUNDAMENTAIS}

Diferentemente do Código Buzaid, composto de 5 livros, o CPC/2015 foi estruturado da seguinte forma: Parte geral (dividida em 6 livros), Parte Especial (composta de 3 livros), Livro complementar (que cuida das disposições finais e transitórias)

Sob a óptica sistêmica, e já debruçando propriamente sobre o tema da abordagem, merece registro a inserção, no Livro I, da parte geral do CPC/2015, de título dedicado às normas fundamentais da jurisdição cível pátria. 
Revista Eletrônica de Direito Processual - REDP.

Rio de Janeiro. Ano 10. Volume 17. Número 2. Julho a Dezembro de 2016

Periódico Semestral da Pós-Graduação Stricto Sensu em Direito Processual da UERJ

Patrono: José Carlos Barbosa Moreira. ISSN 1982-7636. pp. 406-419

www.redp.uerj.br

Ou seja, o CPC/2015 dedicou o capítulo inicial do livro I à parte geral aplicável à jurisdição cível como um todo, mas sem caráter de exclusividade, conforme se verá mais adiante no escrito.

O capítulo, que vai dos artigos $1 .^{\circ}$ ao $12^{\circ}$, recebeu a denominação "Das normas fundamentais sobre o processo civil".

Sobre esse capítulo e algumas de suas implicações nos demais livros do CPC/2015, é que se irá tecer, doravante, uma e outra considerações.

Destaca-se, em primeiro lugar, que o legislador não só previu normas, princípios fundamentais, mas princípios fundamentais de estatura constitucional.

Assim, consolidou-se, no plano legislativo, a chamada constitucionalização do processo, já consagrada no campo doutrinário.

Fenômeno, por óbvio, que não se restringe ao direito processual, eis que todos os ramos do direito devem ser compreendidos à luz da Constituição Democrática brasileira.

De toda maneira, presencia-se expresso reconhecimento, por parte do legislador infraconstitucional, de que sua atividade, como, de resto, a do Judiciário, submete-se, deve submeter-se, salienta-se, aos ditames do Texto Constitucional pátrio.

Antes de abordar alguns destes princípios fundamentais, observação de ordem conceitual merece ser feita.

Dessa maneira, na presente exposição, os princípios serão considerados como diretrizes normativas voltadas à realização de determinado fim (jurídico). ${ }^{4} \mathrm{Ou}$ seja, as normas fundamentais de que se vai cuidar correspondem a diretrizes a partir das quais deverá atuar a jurisdição no Estado Democrático de Direito brasileiro, quer se trate de processo de conhecimento, quer se trate de processo ou fase executiva.

Vejam-se, então, alguns dos princípios fundamentais contemplados no CPC/2015.

\subsection{Princípio da inafastabilidade}

O primeiro princípio a ser abordado é o da inafastabilidade, previsto no art. $3 .^{\circ}$, caput, do CPC/2015.

\footnotetext{
${ }^{4}$ Para análise da estrutura principiológica do CPC/2015, vide BAHIA, Alexandre Franco Melo; NUNES, Dierle; PEDRON, Flávio Quinaud e THEODORO JR., Humberto. NOVO CPC. Fundamentos e Sistematização. Lei 13.105, de 16.03.2015. 2. ed. rev., atual. e ampl. Rio de Janeiro: Forense. $2015 . \quad$ p. 45-68.
} 
Revista Eletrônica de Direito Processual - REDP.

Rio de Janeiro. Ano 10. Volume 17. Número 2. Julho a Dezembro de 2016

Periódico Semestral da Pós-Graduação Stricto Sensu em Direito Processual da UERJ

Patrono: José Carlos Barbosa Moreira. ISSN 1982-7636. pp. 406-419

www.redp.uerj.br

Dito dispositivo reproduz, linhas gerais, o comando inserto no art. $5^{\circ}, \mathrm{XXXV} \mathrm{da}$

CF/1988, segundo o qual “a lei não excluirá da apreciação do Poder Judiciário a alegação de lesão ou ameaça a direito".

A promessa de acesso à justiça no CPC/2015 veio, contudo, disposta sob a forma do que a doutrina denomina de sistema multiportas. ${ }^{5}$

Por outras palavras, além da garantia de que os conflitos poderão ser submetidos ao exame e decisão pelo juiz, colocou-se à disposição das partes formas ditas alternativas de solução de conflitos, tais como a arbitragem, a conciliação e a mediação. ${ }^{6}$

O que se tem de novo, no particular, é a tentativa de profissionalizar tais formas alternativas, notadamente a conciliação e a mediação.

Para tanto, previu-se, no art. 165 do CPC/2015, que os Tribunais poderão criar Centros de conciliação e mediação.

A profissionalização, no caso, será alcançada a partir da exigência de que os conciliadores e mediadores deverão preencher parâmetros curriculares mínimos estabelecidos pelo Conselho Nacional de Justiça em conjunto com o Ministério da Justiça.

Há, inclusive, no art. 174 do CPC/2015, a previsão de instalação de centros de conciliação e mediação para o Poder Público.

Aqui, chama-se a atenção para um ponto: é verdade que a autocomposição se constitui em adequada forma de resolução de conflitos. De outro lado, a previsão destes Centros não pode, em termos práticos, instituir cultura obrigatória de composição “amigável" de conflitos, como forma de diminuir o número de processos e a sobrecarga de trabalho, hoje inegavelmente experimentada pelo Poder Judiciário nacional.

De fato, pois, nesse caso, haverá manifesta violação à autodeterminação das partes e, a rigor, à promessa de acesso à justiça, prevista no art. 5. ${ }^{\circ}, \mathrm{XXXV}$, da CF/1988.

Sem contar que a expressão "composição amigável obrigatória" se constitui, ao fim e ao cabo, em explícita e, por que não dizer, absurda contradição de termos.

\footnotetext{
5 Ao propósito, confira-se FAGUNDES CUNHA, J.S. Da conciliação, da mediação e da arbitragem endoprocessual e o novo Código de Processo Civil. Revista Jurídica Luso-Brasileira. Ano 1, nº 2, 2015. Disponível em: <http://www.cidp.pt/publicacoes/revistas/rjlb/2015/2/2015_02_1095_1129.pdf>. Acesso em: 05.06.2015 e CRUZ E TUCCI, José Rogério. Novo Código de Processo Civil traz mudanças na audiência de conciliação. Disponível em: <http://www.conjur.com.br/2015-out-06/paradoxo-corte-cpctraz-mudancas-audiencia-conciliacao> Acesso em: 04.08.2016.

${ }^{6}$ Em 29 de junho de 2015, foi publicada a Lei 13.140, que disciplina o procedimento da mediação.
} 
Revista Eletrônica de Direito Processual - REDP.

Rio de Janeiro. Ano 10. Volume 17. Número 2. Julho a Dezembro de 2016

Periódico Semestral da Pós-Graduação Stricto Sensu em Direito Processual da UERJ

Patrono: José Carlos Barbosa Moreira. ISSN 1982-7636. pp. 406-419

www.redp.uerj.br

3.2. Princípio da primazia do julgamento de mérito e da duração razoável do processo

Em seguida, no art. 4. $^{\circ}$ do $\mathrm{CPC} / 2015$, cuidou-se do princípio da primazia do julgamento de mérito.

Esse princípio pode ser sintetizado na conhecida assertiva, qual seja "o processo não é um fim em si mesmo". Por outras palavras, o processo existe para responder a demanda levada à análise do Poder Judiciário.

Para viabilizar o exame de mérito, o CPC/2015 conferiu ao juiz, no art. 139, IX, poderes para determinar o suprimento dos pressupostos processuais e o saneamento dos vícios processuais.

Não bastasse essa determinação de ordem geral, portanto, aplicável em todos os graus de jurisdição e espécies de módulos, o CPC/2015, no art. 932, parágrafo único, especificou que o relator, ao exercer o juízo de admissibilidade recursal, deverá conceder à parte recorrente o prazo de 5 dias para sanar irregularidade ou juntar documento.

Daí se conclui que, acertadamente, foi priorizado o julgamento de mérito, tanto no primeiro grau de jurisdição quanto no plano recursal.

Ainda no art. . $^{\circ}$ do CPC/2015, encontra-se a previsão de que a solução integral do conflito deverá ocorrer dentro de um prazo razoável.

Bem, o princípio da duração razoável está consagrado, na Europa, desde a Convenção para a Proteção dos Direitos do Homem e das Liberdades Fundamentais de 1950, sendo previsto, também, na Convenção Americana de Direitos Humanos de 1969, da qual o Brasil é signatário, e na Carta Africana dos Direitos Humanos e dos Povos de 1981.

Há, pois, consenso mundial, e nem poderia ser diferente, quanto à necessidade de o serviço público de justiça produzir resultados úteis.

Para alcançar tal intento, o CPC/2015 prevê série de mecanismos.

A título de exemplo, no art. 191, institui-se técnica de gerenciamento do tempo, denominada calendário processual. ${ }^{7}$

Oriunda do direito francês, por meio dessa técnica será possível às partes e ao juiz, de comum acordo, ajustarem prazos para a prática de atos processuais, inclusive

\footnotetext{
7 Sobre o tema, confira-se ANDRADE, Érico. As novas perspectivas do gerenciamento e da “contratualização" do processo. Revista de Processo. ano 36. vol. 193. São Paulo: RT, mar. 2011.
} 
Revista Eletrônica de Direito Processual - REDP.

Rio de Janeiro. Ano 10. Volume 17. Número 2. Julho a Dezembro de 2016

Periódico Semestral da Pós-Graduação Stricto Sensu em Direito Processual da UERJ

Patrono: José Carlos Barbosa Moreira. ISSN 1982-7636. pp. 406-419

www.redp.uerj.br

realização de audiências, atendendo às peculiaridades do caso concreto, no propósito de obter-se desfecho mais célere para a demanda.

Além disso, nos artigos 303 e 304, disciplina o CPC/2015 a chamada estabilização da tutela antecipada de urgência. ${ }^{8}$

Dita técnica visa a abreviar o procedimento.

Para que haja a estabilização, bastará que o réu não interponha recurso, no caso, o agravo de instrumento, da decisão liminar.

Embora o texto legal mencione apenas a ausência de recurso, o oferecimento de contestação irá configurar inequívoco ato de resistência, a impedir, de igual modo, a estabilização da medida. Ou seja, não sendo impugnada a decisão antecipatória, nem oferecida oposição à pretensão deduzida pelo autor, o juiz irá extinguir o processo por meio de sentença.

No prazo de 2 anos, qualquer das partes poderá instaurar nova demanda para reformar, invalidar ou modificar a decisão em foco.

\subsection{Princípios da boa fé e da cooperação}

Nos artigos $5 .^{\circ}$ e $6 .^{\circ}$ do $\mathrm{CPC} / 2015$, estão previstos os princípios da boa fé e da cooperação.

Estes princípios guardam intimação relação com a noção de comunidade de trabalho desenvolvida (também) no direito processual alemão. Remetem, pois, à ideia de que autor, juiz e réu têm uma espécie de interesse comum (será mesmo?) no desfecho da atividade jurisdicional.

Em suma, o princípio da boa fé impõe aos sujeitos da relação processual, a todos eles, é bom que se diga, o dever de agir de forma objetivamente ética no processo.

Afinal, se mesmo nos contratos e demais negócios jurídicos, em que prepondera o interesse primário de credor e devedor, impõe-se a observância da boa fé objetiva, por maior força de razão, no âmbito do devido processo legal, o agir conforme os ditames da boa fé também deve ser a tônica. Do contrário, a jurisdição poderá ser direcionada para atender prioritariamente interesses particulares, nem sempre legítimos, vale sublinhar.

\footnotetext{
${ }^{8}$ A respeito, vide SOARES, Leonardo Oliveira. Observações pontuais sobre o módulo cognitivo padrão na Lei 13.105/2015. RePro 250/125-126.
} 
Revista Eletrônica de Direito Processual - REDP.

Rio de Janeiro. Ano 10. Volume 17. Número 2. Julho a Dezembro de 2016

Periódico Semestral da Pós-Graduação Stricto Sensu em Direito Processual da UERJ

Patrono: José Carlos Barbosa Moreira. ISSN 1982-7636. pp. 406-419

www.redp.uerj.br

No plano do princípio da cooperação, e dando ênfase ao papel do órgão jurisdicional, ${ }^{9}$ ressalta-se que o juiz tem, basicamente, os deveres:

a) De esclarecimento, notadamente quanto às postulações das partes, o que, numa grosseira comparação, corresponderá a uma espécie de embargos declaratórios às avessas de que o juiz deverá lançar mão para bem compreender e analisar os pleitos de autor e réu.

b) De consulta, que veda manifestações ex officio quanto à matéria fática ou jurídica.

c) De prevenção, a partir do qual cabe ao órgão jurisdicional alertar a parte para a existência de obstáculos formais que possam prejudicar ou mesmo inviabilizar o exame de mérito.

Um exemplo do princípio da cooperação no CPC/2015 envolve a hipótese de emenda da petição inicial.

Isso porque, nos termos do art. 321 do $\mathrm{CPC} / 2015$, ao verificar que a inicial não contempla determinada exigência legal, deverá o juiz não só intimar o autor para emendar a inicial, mas indicar, com precisão, o que deve ser corrigido.

Apenas na hipótese de o requisito previamente apontado não ser preenchido, poderá o juiz, enfim, indeferir a inicial.

\subsection{Princípio do contraditório dinâmico}

Dando sequência à abordagem, há o princípio do contraditório dinâmico.

Esse princípio engloba o direito de as partes influenciarem a decisão, além da proibição de o juiz proferir decisões surpresa no processo.

Como os artigos $7 .^{\circ}, 9 .^{\circ}$ e 10 do $\mathrm{CPC} / 2015$ cuidam da garantia do contraditório, será feita rápida análise conjunta de tais dispositivos.

Isso para destacar, uma vez mais, ${ }^{10}$ que a inserção desses dispositivos poderá representar a grande contribuição do CPC/2015 para a democratização do processo jurisdicional brasileiro.

\footnotetext{
${ }^{9}$ Esclareça-se que não se está a defender necessária colaboração direta as partes do processo, haja vista a amplitude do constitucional direito de ampla defesa no Estado Democrático de Direito brasileiro.

${ }^{10}$ A respeito, vide SOARES, Leonardo Oliveira. Observações pontuais sobre o módulo cognitivo padrão na Lei 13.105/2015. RePro250/127-129.
} 
Revista Eletrônica de Direito Processual - REDP.

Rio de Janeiro. Ano 10. Volume 17. Número 2. Julho a Dezembro de 2016

Periódico Semestral da Pós-Graduação Stricto Sensu em Direito Processual da UERJ

Patrono: José Carlos Barbosa Moreira. ISSN 1982-7636. pp. 406-419

www.redp.uerj.br

E de que forma tal contribuição irá se materializar? Explica-se. Ao romper com a

noção tradicional de vínculo de subordinação, no qual autor e réu estariam sujeitos ao poder do juiz, propicia-se, em ambiente de igualdade, que os argumentos de fato e de direito apresentados pelas partes sejam considerados, tornando, nessa perspectiva, as partes como coautores da decisão judicial.

\subsection{Princípio da transparência ou da impessoalidade processual}

Prosseguindo, veja-se a norma contida no art. 12 do CPC/2015. ${ }^{11}$

Conforme esse dispositivo, os processos aptos para julgamento deverão observar ordem cronológica de conclusão, sendo que a lista contendo essa ordem deverá ficar à disposição das partes, seja na secretaria do juízo, seja na rede mundial de computadores.

Destaca-se que tal ordem de julgamento não é inflexível, comportando exceções, por exemplo, em se tratando de requerimento de medidas urgentes.

Em primeira leitura, o artigo poderia ser visto como uma espécie de desconfiança do legislador em relação aos juízes. Prefere-se, contudo, analisar o dispositivo tão só pela óptica da transparência, tentativa de se organizar o exercício da função jurisdicional, a partir de um dado objetivo, qual seja, a data em que os autos em condições de julgamento foram "enviados", ainda que virtualmente, ao juiz.

Para conferir autonomia à diretriz contida no art. 12, diferenciando-a dos princípios da isonomia e da publicidade dos julgamentos, assegurados nos artigos $7 .^{\circ} \mathrm{e}$ 11 do CPC/2015, esse dispositivo geral será chamado de princípio da transparência ou da impessoalidade processual.

Ainda dois últimos princípios, de índole infraconstitucional, é verdade, merecem ser analisados.

\subsection{Princípio da aplicação imediata}

Tal princípio encontra-se disposto no art. 14 do CPC/2015.

11 O PLC 168/2015, convertido na Lei 13.256, publicada em 05 de fevereiro de 2016, modificou o CPC/2015 para estabelecer que a ordem de julgamento será "preferencialmente" a estabelecida no artigo em tela. Em termos práticos, de pouca ou nenhuma utilidade se apresentará o dispositivo alterado, haja vista a maleabilidade do respectivo comando. 
Revista Eletrônica de Direito Processual - REDP.

Rio de Janeiro. Ano 10. Volume 17. Número 2. Julho a Dezembro de 2016

Periódico Semestral da Pós-Graduação Stricto Sensu em Direito Processual da UERJ

Patrono: José Carlos Barbosa Moreira. ISSN 1982-7636. pp. 406-419

www.redp.uerj.br

Aludido comando normativo estatui que os processos em curso no Brasil, aproximadamente 100 milhões nos dias de hoje, ${ }^{12}$ deverão seguir as disposições do futuro

CPC, desde que se observe a teoria do isolamento dos atos processuais

Linhas gerais, pode dizer-se que os atos processuais praticados até 17 de março de 2016 permanecerão válidos, devendo, daí em diante, a cadeia procedimental ser regida pelo CPC/2015. ${ }^{13}$

Acredita-se que, em primeiro momento, poderá haver significativa perturbação no funcionamento do Poder Judiciário.

Entre outros fatores, em virtude do desconhecimento mesmo das novas regras processuais, ou, ainda, pela equivocada, maliciosa ou não, interpretação do alcance da teoria do isolamento dos atos processuais.

\subsection{Princípio da subsidiariedade mitigada.}

Finalmente, prevê o artigo 15 do CPC/2015 a incidência supletiva e subsidiaria de suas regras, na ausência de normas que regulem processos eleitorais, militares e administrativos,

Aqui, chama-se a atenção para um ponto particular, a saber, o CPC/2015 poderá se oferecer como possível fonte normativa para a democratização da Administração Pública brasileira.

Isso porque, ao menos numa primeira leitura, tanto o princípio do contraditório dinâmico ${ }^{14}$ quanto o princípio da fundamentação analítica, abordados faz pouco, deverão ser observados nos procedimentos instaurados na órbita executiva.

Desse modo, os argumentos, seja do servidor público, seja do administrado, deverão ser levados em conta no momento decisório, não podendo o Administrador

\footnotetext{
12 Consoante dados divulgados pelo CNJ no relatório Justiça em Números de 2015. Disponível em: <http://www.cnj.jus.br/programas-e-acoes/politica-nacional-de-priorizacao-do-1-grau-dejurisdicao/dados-estatisticos-priorizacao>. Acesso em: 30.07.2016.

${ }^{13}$ Caso a faculdade em concreto para a prática do ato no processo tenha como termo inicial data anterior a 18 de março de 2016, haverá de ser observada a lei processual vigente, no caso, o art. 1.211 do CPC de 1973. Ainda que o ato, efetivamente, venha a ser praticado após o dia 18 de março de 2016.

14 Em defesa da aplicação do princípio da não surpresa nos processos instaurados no âmbito da Administração Pública, consulte-se SOARES, Leonardo Oliveira. A democratização da Justiça. Jornal Estado de Minas, Caderno Direito \& Justiça, edição de 26 de fevereiro de 2016 e SOUZA, Artur César. Aplicação subsidiária do novo CPC ao processo administrativo. RePro 256/445.
} 
Revista Eletrônica de Direito Processual - REDP.

Rio de Janeiro. Ano 10. Volume 17. Número 2. Julho a Dezembro de 2016

Periódico Semestral da Pós-Graduação Stricto Sensu em Direito Processual da UERJ

Patrono: José Carlos Barbosa Moreira. ISSN 1982-7636. pp. 406-419

www.redp.uerj.br

Público proferir decisões surpresa que venham imputar responsabilização ao servidor, ou mesmo negar direitos ao administrado/cidadão.

Em suma, a mesma oxigenação, por assim dizer, que se espera venha a ocorrer no plano da jurisdição, poderá ser experimentada na esfera da Administração Pública, o que, ao fim e ao cabo, irá contribuir, oxalá, para o fortalecimento institucional do regime democrático brasileiro.

\section{A TÍTULO DE CONCLUSÃO}

Dito isso, finaliza-se a exposição justificando a escolha do título: "O novo Código de Processo Civil brasileiro: um Código de princípios."

Bem, já houve época em que era comum ser utilizada a expressão "ali vai um homem de princípios" quando se pretendia enaltecer o caráter de uma pessoa, ressaltando os propósitos de suas ações.

Nesse sentido, poder-se-ia supor que se está a depositar todas as fichas no $\mathrm{CPC} / 2015$.

Realmente, pois, ao dedicar parte geral a princípios prioritariamente constitucionais, estaria cogitado Código supostamente comprometido com nobilíssimo propósito, qual seja, dar concretude ao justo processo civil, ao giusto processo civile, para empregar expressão bem ao gosto da mais moderna doutrina processual.

Afirmo-lhe, então, crédulo leitor, que a implementação de tais propósitos dependerá, em essência, da atuação prática de todos aqueles que estejam envolvidos na prestação da tutela jurisdicional, ou melhor, no denominado sistema multiportas de acesso à justiça.

Em síntese, acertou o legislador ao consagrar o capítulo inicial do CPC/2015 às normas fundamentais regentes da jurisdição pátria.

Com efeito, pois aludidos comandos, conforme visto ao longo do texto, podem proporcionar, dentre outros desdobramentos, maior brevidade na resolução de conflitos, sem prejuízo, em todo caso, da democratização do processo de construção de decisões, em vista da valorização do diálogo entre os respectivos interessados. 
Revista Eletrônica de Direito Processual - REDP.

Rio de Janeiro. Ano 10. Volume 17. Número 2. Julho a Dezembro de 2016

Periódico Semestral da Pós-Graduação Stricto Sensu em Direito Processual da UERJ

Patrono: José Carlos Barbosa Moreira. ISSN 1982-7636. pp. 406-419

www.redp.uerj.br

No particular, merece destaque a roupagem legislativa conferida à garantia constitucional do contraditório, vetor central para a resolução de conflitos no Estado Democrático de Direito brasileiro.

A consagração de normas fundamentais não levará, entretanto, a uma por assim dizer obrigatória tomada de decisões compatíveis com o modelo constitucional de processo disposto na CF/1988, seja na seara jurisdicional, seja na esfera da Administração Pública.

Afinal, não dispõe o direito processual, como, de resto, o direito, em seu todo considerado, de vida própria.

Bem por isso, pode encerrar-se o escrito relembrando a sábia advertência popular, segundo a qual "de boas intenções o inferno está cheio".

\section{REFERÊNCIAS BIBLIOGRÁFICAS}

ANDRADE, Érico. As novas perspectivas do gerenciamento e da "contratualização" do processo. Revista de Processo. ano 36. vol. 193. São Paulo: RT, mar. 2011.

BAHIA, Alexandre Franco Melo; NUNES, Dierle; PEDRON, Flávio Quinaud e THEODORO JR., Humberto. NOVO CPC. Fundamentos e Sistematização. Lei 13.105, de 16.03.2015. 2. ed. rev., atual. e ampl. Rio de Janeiro: Forense. 2015.

BRASIL. Conselho Nacional de Justiça. Dados estatísticos. Disponível em: <http://www.cnj.jus.br/programas-e-acoes/politica-nacional-de-priorizacao-do-1-graude-jurisdicao/dados-estatisticos-priorizacao>. Acesso em: 30.07.2016

CRUZ E TUCCI, José Rogério. Novo Código de Processo Civil traz mudanças na audiência de conciliação. Disponível em: <http://www.conjur.com.br/2015-out06/paradoxo-corte-cpc-traz-mudancas-audiencia-conciliacao>. Acesso em: 04.08.2016. FAGUNDES CUNHA, J.S. Da conciliação, da mediação e da arbitragem endoprocessual e o novo Código de Processo Civil. Revista Jurídica Luso-Brasileira. Ano 1, nº 2, 2015. Disponível em: <http://www.cidp.pt/publicacoes/revistas/rjlb/2015/2/2015_02_1095_1129.pdf>. Acesso em: 05.06.2015.

SOARES, Leonardo Oliveira. Observações pontuais sobre o módulo cognitivo padrão na Lei 13.105/2015. Revista de Processo. ano 40. vol. 250. São Paulo: Ed. RT, dez. 2015. 
Revista Eletrônica de Direito Processual - REDP.

Rio de Janeiro. Ano 10. Volume 17. Número 2. Julho a Dezembro de 2016

Periódico Semestral da Pós-Graduação Stricto Sensu em Direito Processual da UERJ

Patrono: José Carlos Barbosa Moreira. ISSN 1982-7636. pp. 406-419

www.redp.uerj.br

. A democratização da Justiça. Jornal Estado de Minas, Caderno Direito \&

Justiça, edição de 26 de fevereiro de 2016.

SOUZA, Artur César. Aplicação subsidiária do novo CPC ao processo administrativo.

Revista de Processo. ano 41. vol. 256. p. 441-454. São Paulo: Ed. RT, jun. 2016. 